Article

\title{
Evaluating Consumers' Adoption of Renewable Energy
}

\author{
Bilal Khalid ${ }^{1}$ (D), Mariusz Urbański ${ }^{2, * \mathbb{D}}$, Monika Kowalska-Sudyka ${ }^{2}$, Elżbieta Wysłocka ${ }^{3}$ and Barbara Piontek $^{4}$ \\ 1 KMITL Business School, King Mongkut's Institute of Technology Ladkrabang, Bangkok 10520, Thailand; \\ khalidb9998@gmail.com \\ 2 Road and Bridge Research Institute, 03-302 Warszawa, Poland; mkowalska@ibdim.edu.pl \\ 3 Faculty of Management, Częstochowa University of Technology, 42-201 Częstochowa, Poland; \\ elzbieta.wyslocka@wz.pcz.pl \\ 4 Faculty of Applied Sciences, WSB University, 41-300 Dąbrowa Górnicza, Poland; bpiontek@wsb.edu.pl \\ * Correspondence: murbanski@ibdim.edu.pl
}

Citation: Khalid, B.; Urbański, M.; Kowalska-Sudyka, M.; Wysłocka, E.; Piontek, B. Evaluating Consumers' Adoption of Renewable Energy. Energies 2021, 14, 7138. https:// doi.org/10.3390/en14217138

Academic Editors: Beata Ślusarczyk, József H.c. Popp and Judit Oláh

Received: 24 September 2021

Accepted: 26 October 2021

Published: 1 November 2021

Publisher's Note: MDPI stays neutral with regard to jurisdictional claims in published maps and institutional affiliations.

\begin{abstract}
The purpose of this study was to evaluate the consumers' adoption of renewable energy in Poland. The study focused on finding out the factors that influence the adoption of the technology, considering its importance in conserving the environment. The study was conducted using a quantitative method, with primary data collected from 467 households using renewable energy technology in Poland. The research adopted the TAM model. The independent variables of the study included renewable energy initial cost, environmental concern, risk and trust for renewable energy, ease of use, financial incentives, and relative advantage. The dependent variable was renewable energy adoption. Structural equation modelling (SEM) was used to analyze the study hypotheses. The research found out that environmental concerns, ease of use, financial incentives, and relative advantage have a positive and significant influence on adoption of renewable energy technology in Poland. However, renewable energy initial cost and risk, and trust for renewable energy did not significantly influence renewable energy adoption. The study recommended that the stakeholders should consider the aspects of environmental concern as a key role player in pushing for adoption of renewable energy. The government, non-governmental organizations, and concerned stakeholders should consider giving incentives towards renewable energy adoption. Creating awareness regarding the benefits and strengths of renewable energy should be prioritized to the households.
\end{abstract}

Keywords: renewable energy; green environment; technology adoption; technology acceptance model

\section{Introduction}

Renewable energies involve energies harnessed from natural resources that can be replenished constantly. Often referred to as clean energy, renewable energy involves energies from solar energy, wind energy, geothermal energy, and water. Renewable energy is considered a new technology as it replaces the traditional forms of energy from fossil fuels that cannot be replaced [1]. The increasingly innovative ways to harnessing renewable energy continue to become important worldwide, replacing the non-renewable forms of energy such as oil, gas, and coal. Unlike the non-renewable forms of energy, renewable energy technologies are considered clean energy as they do not release pollutants such as carbon dioxide and greenhouse gases [2].

Although renewable energy technologies are considered a new phenomenon, renewable energy has been in use for centuries. For instance, humans have relied on the sun for lighting and heat, whereas water and windmills were used to power granaries [3]. Subsequently, the increased dependency by humans on non-renewable energies such as fossil fuels has led to widespread detrimental effects on the planet, including climate change.

The recent technological advancements in harnessing natural energies offer solutions to replacing the traditional non-renewable energies. For instance, the use of solar panels on both small and large scales offers solutions to the production of clean energy from 
solar energy [4]. Renewable energies harnessed from natural resources by renewable technologies can be used for electricity, transportation, and heating, among other functions.

There are various sources of renewable energy technologies that can be adopted as alternative forms of energy from traditional fossil fuel energies. For instance, solar energy is harnessed from the sun [5]. Solar energy is tapped from the sun through the solar systems that convert the sunlight to the energy for heating and lighting. Solar-powered technologies include solar panels and are considered clean energy sources [6]. In 2019, solar energy contributed to $2 \%$ of global electricity. Wind power is another type of renewable energy that is harnessed through wind turbines. Wind energy is used to turn turbine blades that feed electric generator producing electricity [7]. Wind power energy has been widely adopted across the world; in Europe, for instance, wind power provides 14\% of Europe's electricity.

Another form of renewable energy is hydropower. Hydropower energy is harnessed from moving water to generate electricity. Often, plants are located near elevated moving water sources that are used to turn turbine blades, which in turn spin the generator that is used in the production of electricity. The amount of hydroelectric power generated depends on both the volume and flow of water to turn the generator turbines [1]. The adoption of hydropower is one of the largest around the world, with $36 \%$ of electricity across Europe being generated from hydropower. Biomass is another form of renewable energy technology that involves the generation of energy from organic materials from plants and animals. Plants contain chemical energy from the sun and can be converted to energy through direct combustion, chemical conversion to produce liquid fuels, and other forms. Biomass is considered one of the highest contributors to renewable energy. Across Europe, biomass contributes to $4 \%$ of the total energy supply.

The increasing energy demand is accelerated by the increasing economic growth on the global scale. Similarly, the increasing environmental changes resulting from economic growth have led to the depletion of natural resources, necessitating the need for alternative sources of energy from traditional fossil fuels. Poland is one of the countries in Europe that depends heavily on traditional sources of energy, including coal, to produce energy. However, Poland has, over the years, embarked on the adoption of renewable energies, and in 2017, renewable energy in the country accounted for 14\% of electricity. In 2016, Poland, through the National Renewable Energy Action Plan, committed to generating $15 \%$ of its energy from renewable sources by 2020. In 2021, the country increased its target, aiming to pursue at least $23 \%$ of renewable energy consumption by 2030 [8].

Renewable energy adoption in Poland has been remarkable over the years; however, the country needs to increase its consumption to meet its 2030 renewable energy policy targets [8]. Based on the Polish national renewable energy action plan, the country's renewable energy market is dominated by biomass. Biomass is the most abundant form of renewable energy in Poland because it is easy to use and involves the direct burning of solid and gaseous biofuels. Other forms of renewable energies in Poland include wind power energy, which produces an approximated $5.8 \mathrm{GW}$. Poland is ranked seventh in the European Union in the production of wind power energy [8]. The country also produces solar energy, which is viewed by many in the country as the alternative form of energy to traditional fossil fuels. By 2019, the adoption level of solar energy in Poland was estimated to total 700 megawatts.

From the background presented above, it is evident that renewable energy is a necessary commodity in Polish households. This study, however, does not measure the perceived usefulness and attitude of Polish residents towards the use of renewable energy. This is because the variable that measures relative advantage addressed this usefulness from an external point of view. Hence, the perceived usefulness was not considered an important variable to assess in this study.

Energy is also needed as an environmentally conservative alternative source. However, the adoption of technology is not well implemented, considering the market needs. As well, the aspects influencing its adoption have not been researched in Poland. Therefore, given 
the increasing demand of renewable energy in Poland, the associated benefits emanating from adopting the technology, and the increased efforts by various stakeholders to adopt the technology, this study bridges this gap by investigating the factors influencing renewable energy technology adoption in Poland.

The research will be guided by two major research questions: (1) What are the factors influencing consumers' adoption of renewable energy in Poland? And (2) What are the recommendations to stakeholders regarding the adoption of renewable energy in Poland? The research has several sections. The introduction gives the background of the paper, and the literature review evaluates the previous research related to this study. The methodology presents the techniques adopted in the study, the results section presents the findings of the study, and the discussion evaluates the findings in relation to the previous literature, concludes and develops the implications and recommendations of the research.

\section{Literature Review}

The purchase behavior of consumers is a complicated process, which is influenced by many factors. In an attempt to explain the purchase behavior of consumers, several theoretical models have been developed, including theory of reasoned action (TRA), theory of planned behavior (TPB), technology acceptance model (TAM, TAM2), and unified theory of acceptance and use of technology (UTAUT). Among them, TAM was considered for this study as it addresses the individual's acceptance behavior motivated by external factors surrounding the technology. TAM adoption was also motivated by the fact that renewable energy is relatively a new technology in Poland. From the TAM model, the factors adopted were: external factors (initial cost, environmental concern, risk and trust, financial incentives, relative advantage), ease of use, and renewable energy adoption (representing actual use of technology). These factors and the TAM model are expounded in the following sections.

\subsection{Factors Affecting Renewable Energy}

The development of renewable energy in various countries around the world is dependent on the drivers as well as barriers to renewable energy. According to [9,10], there are various determinates, including legal, physical, and mental, that influence renewable energy adoption. In Poland, the adoption of renewable energy is considered one of the key technologies that will ensure meeting future energy needs and meeting sustainable development in the country. However, various factors impact the production and consumption of renewable energy, as well as its adoption.

\subsubsection{Initial Costs (IC)}

Although the benefits of using a new technology [11] such as renewable energy sources are enormous, attaining a full switch to renewable energy use is not yet viable due to the various aspects involved in the development of these energy sources. Costs are the most significant challenges in the adoption of renewable energy in many countries. The costs associated with the development of renewable energy include the building and installing of the facilities [12-14]. For instance, solar and wind energy sources are cheap as they involve the use of free energy from the sun and wind; however, the majority of the costs are in the initial phases of installation. In Poland, the average cost in the installation of solar panels is $\$ 15,500$ [8], whereas the cost of storage of renewable energy is estimated at 9 cents per hour. The high initial costs for renewable energy adversely affect the consumer's perception of renewable energy, leading to the slow adoption of the new technologies. Similarly, financial institutions aiming to lend finances towards the development of renewable energy may perceive the ventures as being risky, leading to higher lending rates for renewable energy developers. 


\subsubsection{Environmental Concern (EC)}

The use of energy impacts the environment in different ways. Energy sources based on fossil fuels are known to contribute to negative environmental effects, including the production of greenhouse gases that contribute to climate change [15]. Environmental concerns impact the production and adoption of renewable energy as it presents as an alternative to fossil fuels in the preservation of the environment. According to [16], renewable energy produces $99 \%$ fewer greenhouse gases compared to the energy from traditional coal and oil. The use of renewable energy is critical in ensuring environmental conservation through reducing global warming and, consequently, climate change $[17,18]$. The increased environmental concerns positively impact the adoption and use of renewable energy.

\subsubsection{Risks and Trust (RT)}

Trusts play a vital role in financing renewable energy infrastructure; however, the use of trusts is vulnerable to the changes in power prices and other risks associated with renewable energy influencing its adoption. According to [8], renewable energy investment continues to grow strongly; however, the investment is dependent on the various risks associated with renewable energy. Poland is one of the leading countries in Eastern Europe in the development of renewable energy [19]. The increased growth in the development of renewable energy in the country has seen an increase in global renewable energy investors to Poland, positively influencing the development of renewable energy. However, the renewable energy sector faces various risks that may affect the investment trust. For instance, political and regulatory risks influencing the development of renewables affect the rate of investment trusts in the country and consequently the rate of renewable energy adoption. Poland is one of the remaining countries in Europe that recently introduced the feed-in-tariffs (FiT) aimed at promoting the renewable energy sector. Having few renewable energy risks helps in attracting renewable energy investment trusts and consequently leads to an increased in renewable energy adoption.

\subsubsection{Ease of Use (EU)}

The process of adopting renewable energy may be complex, necessitating the need to streamline the various processes to ensure the achievement of sustainability [20-23]. The consumer's willingness to adopt new renewable technologies depends on the complexities of using renewable energy. In the study by [6], the author articulates that although many people are willing to adopt the use of renewable energy in their homes, the process towards the adoption is often affected by income. The belief that renewable energy is associated with high costs of application negatively impacts the willingness of consumers to use renewable energy [24-26]. Uncertainty in business also contributes to the complexity of the adoption of renewable energy [27]. Business competition influences the energy prices in the markets that in turn influence the level of renewable energy. Favorable conditions leading to lower energy prices have the effect of influencing increased willingness to adopt renewable energy [28,29]. In Poland, the willingness to adopt renewable energy is affected by aspects including peer support, age, income, and environmental attitudes of consumers. This link has been previously used in other researches, but for this case, different observational factors related to renewable energy in Poland were applied.

\subsubsection{Financial Incentives (FI)}

Financial incentives play a critical role in the promotion and adoption of renewable energy around the world. Governments keen on promoting the adoption of renewable energy to promote sustainable growth use financial incentives to address the various challenges hindering the development of renewable energy. For instance, financial incentives help reduce the high initial costs associated with the installation of renewable energy infrastructure [1]. Although much of renewable energy involves the use of free resources such as wind and sunlight, huge capital is involved in the development of infrastructure, such as the installation of wind turbines in the generation of wind power [30-32]. Financial 
incentives help improve the ease to access to capital and positively impact the adoption of renewable energy. Poland's renewable energy sources receive financial incentives from the government in the form of subsidy and loan schemes, the quota system, and tax relief. An increased financial incentive towards renewable energy has the effect of increased adoption rates among consumers.

\subsubsection{Relative Advantage (RA)}

The relative advantage in technology involves the degree to which a particular innovation is superior to the traditional methods. Renewable energy technologies compete with traditional sources of energy, including fossil fuels [33] and their installations [34]. The relative advantage in energy can thus be measured based on convenience, satisfaction, economic terms, and social prestige factors. The increased awareness of the effects of climate change has increased the social concerns towards the adoption of green energy. Thus, the need to ensure environmental sustainability comes as a relative advantage towards the adoption of renewable energy compared to traditional fossil fuel energy. In the study by [16], 80\% of energy consumers in Poland consider environmental protection important to ensure sustainability. The pro-environmental attitudes in Poland act as a relative advantage towards the adoption of renewable energy in the country. A greater relative advantage towards renewable energy helps in increasing the adoption rates.

\subsection{Theoretical Literature and Model Development}

The technology acceptance model (TAM), which was adopted for this study, predicts the intention to accept technology by individual users $[35,36]$. The model, developed by Davis [37], highlights the various factors that influence individual behavior towards the use of the new technology. The technology acceptance model (TAM) suggests that the level of acceptability of new technology by individuals is determined by factors including the perceived ease of use and the perceived usefulness.

The perceived usefulness refers to the degree to which the individuals believe the use of a particular technology will enhance their performance [38,39]. Technology is often utilized to enhance performance, and individuals will pick particular types of technology based on the belief that the technology will be useful in attaining their goals. The idea of the perceived usefulness of new technology is considered as the determinant of the actual behavior of individuals towards new technology. In the scenario involving the adaptation of renewable energy, the concept of perceived usefulness involves the degree of belief in the usefulness of the technology towards improving their performance [40]. Because this study seeks to place more emphasis on external factors that influence the adoption of renewable energy, perceived usefulness will not be considered as a variable as proposed in studies such as [38-41].

Relative advantage is also considered as a variable that can give an indication into the perceived usefulness of a technology. Study [42] argues that although there are conceptual differences between relative advantage and perceived usefulness, they have been used interchangeably by researchers. Because the study variables are mainly external variables, the researchers believe that relative advantage of adopting renewal energy sources can be used to replace perceived usefulness. However, when the study is based mainly on internal variables, it would be expedient to include perceived usefulness as a variable as it would answer questions that go beyond external validations of adopting a technology, but it also addresses issues that are personal to the respondents, especially, how useful they consider the technology, which ultimately influences the attitude towards it adoption [43].

The perceived ease-of-use, on the other hand, refers to the level of belief by individuals that the technology will be free of effort. According to scholars $[37,44]$, where technology is perceived to be easy to use, individuals are likely to create positive attitudes towards the new innovation. However, where the technology is considered to be complicated, then it is also likely that individuals will develop a negative attitude towards the new innovation [45]. Often, consumers are likely to perceive new technology as being better 
than the similar existing technologies [46]. In the case of renewable energy technologies, individuals are likely to consider the new energy technologies due to the ease of evaluating the benefits compared to other forms of traditional energy.

\subsection{Conceptual Framework}

From the critical review of the previous literature, and the adoption of the TAM model above, the conceptual framework was developed. The model contains six latent variables, with a varying number of observed variables. The latent variables include Renewable Energy Initial Cost (IC), Environmental Concern (EC), Renewable Energy Risk and Trust (RT), Ease of Use (EU), Financial Incentives (FI), and Relative Advantage (RA). The dependent variable is Renewable Energy Adoption (REA). The scales adopted for the study are attached in the Appendix A. The research model is presented in the Figure 1.

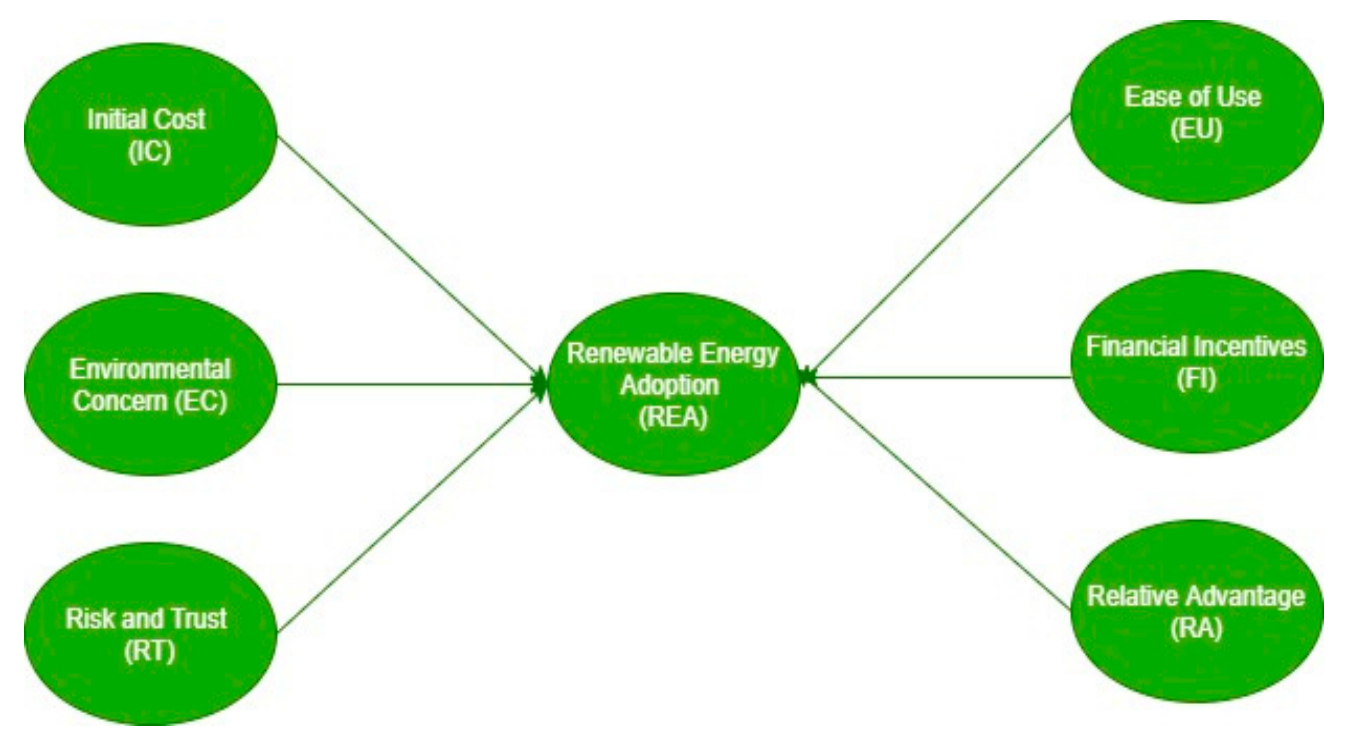

Figure 1. Research model.

From the above conceptual framework, adopted theory, and consulted literature review, the following hypotheses were developed:

Hypothesis 1 (H1). Initial costs have a significant and negative effect on renewable energy adoption in Poland.

Hypothesis 2 (H2). Environmental concerns have a significant and positive effect on renewable energy adoption in Poland.

Hypothesis 3 (H3). Risk and trust have a significant and positive effect on renewable energy adoption in Poland.

Hypothesis 4 (H4). Ease of use has a significant and positive effect on renewable energy adoption in Poland.

Hypothesis 5 (H5). Financial Incentives have a significant and positive effect on renewable energy adoption in Poland.

Hypothesis 6 (H6). Relative Advantage has a significant and positive effect on renewable energy adoption in Poland. 


\section{Research Methods}

The study consisted of the renewable energy consumers' survey using a structured questionnaire. The questionnaire was divided in to two major sections: the first section contained demographic questions and the second section contained renewable energy adoption questions. The questions contained a 5-point Likert scale.

The study population was the household members who intended to use and those that were already using renewable energy in Poland, which were represented by a sample from which the study data were collected. The data were collected in the rural and urban areas of Poland between January 2021 and August 2021. The questionnaire was sent to the targeted respondents through email, where they were required to complete and submit Google forms. A total of 600 respondents were targeted, among which 467 respondents gave suitable feedback that was used for the data analysis.

The first analysis involved the verification of the study model. This was done using reliability and validity analysis using techniques such as composite reliability (CR) and average variance extracted (AVE). This evaluated the suitability of the analysis model, and the potential reliability of the analysis. Another analysis that was conducted was of the descriptive statistics, which evaluated the demographic characteristics of the respondents, such as age, gender, and occupation. The evaluation of the study was done using the structural equation modeling (SEM). The analysis was conducted using AMOS vs. 26 and SPSS vs. 23.

\section{Results}

Table 1 shows the demographic characteristics of the respondents. From the results, the majority of the respondents were female, comprising $63 \%$, and males comprised $37 \%$. Considering the age, the majority of respondents were in the age group 30-40 years followed by those aged 18-30 years. The smallest age group category was above 60 years. For education, the highest education as those with diplomas consisting of $59 \%$ followed by those with high school or lower level of education. The research also investigated the occupation of the respondents, and most of them were self-employed, represented by $37 \%$, followed by those with technical jobs, comprising $36 \%$.

Table 1. Demographics of respondents.

\begin{tabular}{ccc}
\hline & $\mathbf{n}$ & \% \\
\hline Gender & 172 & 36.8 \\
Male & 295 & 63.2 \\
Female & & \\
Age & 100 & 21.4 \\
18-30 Years & 248 & 53.1 \\
30-45 Years & 77 & 16.5 \\
50-60 Years & 42 & 9 \\
Above 60 Years & & \\
Highest Education Level & 99 & 21.2 \\
High School or Lower & 276 & 59.1 \\
Diploma & 90 & 19.3 \\
Graduate & 2 & 0.4 \\
Post-Graduate/Higher & & 35.5 \\
Occupation & 166 & 10.5 \\
Technical Jobs & 49 & 7.3 \\
Company Employee & 34 & 37 \\
Government Officer & 173 & 9.6 \\
Self-Employed & 45 & \\
Others & &
\end{tabular}

Table 2 and Figure 2 shows the results of confirmatory factor analysis (CFA). The first CFA analysis was conducted, but one measure of indices (NFI) was below the threshold. 
The model was evaluated using the modification indices and the error terms with high modification indices were correlated. As a result, the CFA indices improve to acceptable levels as shown in the "adjusted model" column in Table 2 below. The thresholds, according to [47-51], were within the acceptable threshold.

Table 2. CFA Fit Indices.

\begin{tabular}{ccccc}
\hline CFA Indices & Threshold & First Model & $\begin{array}{c}\text { Adjusted } \\
\text { Model }\end{array}$ & Status \\
\hline CMIN/df & $<3.00$ & 2.014 & 1.889 & Satisfactory \\
RMSEA & $<0.08$ & 0.049 & 0.044 & Satisfactory \\
CFI & $>0.90$ & 0.943 & 0.954 & Satisfactory \\
TLI & $>0.90$ & 0.936 & 0.949 & Satisfactory \\
NFI & $>0.90$ & 0.897 & 0.908 & Satisfactory \\
IFI & $>0.90$ & 0.943 & 0.955 & Satisfactory \\
Overall & & & & Satisfactory \\
\hline
\end{tabular}

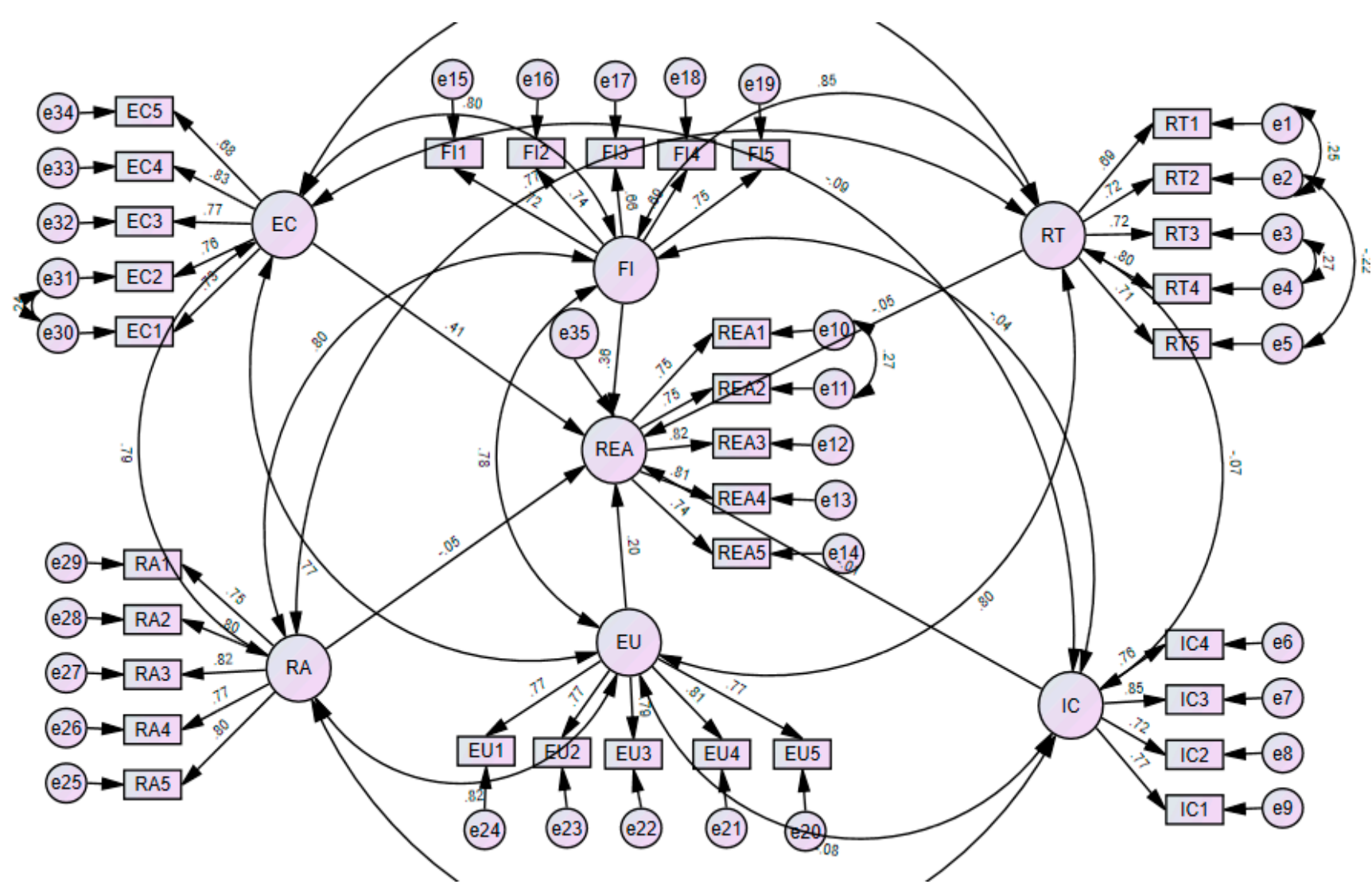

Figure 2. Confirmatory factor analysis.

Discriminant validity was conducted to evaluate whether the tests of the concepts were highly correlated with other tests that are designed to measure theoretically different concepts. The required threshold that the square root of AVE was greater than interconstruct correlations was met. This is presented in Table 3.

Table 4 shows that all the standardized factor loadings were above the threshold of 5.0 according to [48]. The reliability conducted by composite reliability (CR) and validity results conducted by average variance extracted (AVE) is presented in the Table 4 . The composite reliability of all the study variables ranged from 0.787 to 0.854 . These figures were all above 7.0 thresholds as stipulated by [52]. For the AVE, the values ranged from 0.503 to 0.644 , which satisfied the set threshold of 5.0 according to [53]. 
Table 3. Discriminant validity.

\begin{tabular}{cccccccc}
\hline & EC & EU & FI & IC & RA & REA & RT \\
\hline EC & 0.814 & & & & & & \\
EU & 0.674 & 0.830 & & & & & \\
FI & 0.685 & 0.678 & 0.777 & & & & \\
IC & -0.071 & -0.069 & -0.036 & 0.814 & & & \\
RA & 0.699 & 0.740 & 0.698 & -0.048 & 0.835 & & \\
REA & 0.678 & 0.641 & 0.661 & -0.070 & 0.625 & 0.831 & \\
RT & 0.645 & 0.689 & 0.717 & -0.062 & 0.672 & 0.592 & 0.796 \\
\hline
\end{tabular}

Table 4. Reliability and validity results.

\begin{tabular}{ccc}
\hline Variable & CR & AVE \\
\hline IC & 0.794 & 0.543 \\
EC & 0.841 & 0.521 \\
RT & 0.854 & 0.503 \\
EU & 0.853 & 0.516 \\
FI & 0.822 & 0.644 \\
RA & 0.787 & 0.581 \\
\hline
\end{tabular}

Note: IC = Initial Cost; EC = Environmental Concern; RT = Risk and Trust; EU = Ease of Use; FI = Financial Incentives; RA = Relative Advantage.

The structural equation modeling (SEM) was the major statistical analysis of this research, which was aimed at evaluating the hypotheses of the study. The output of the SEM analysis is presented in Figure 3 below.

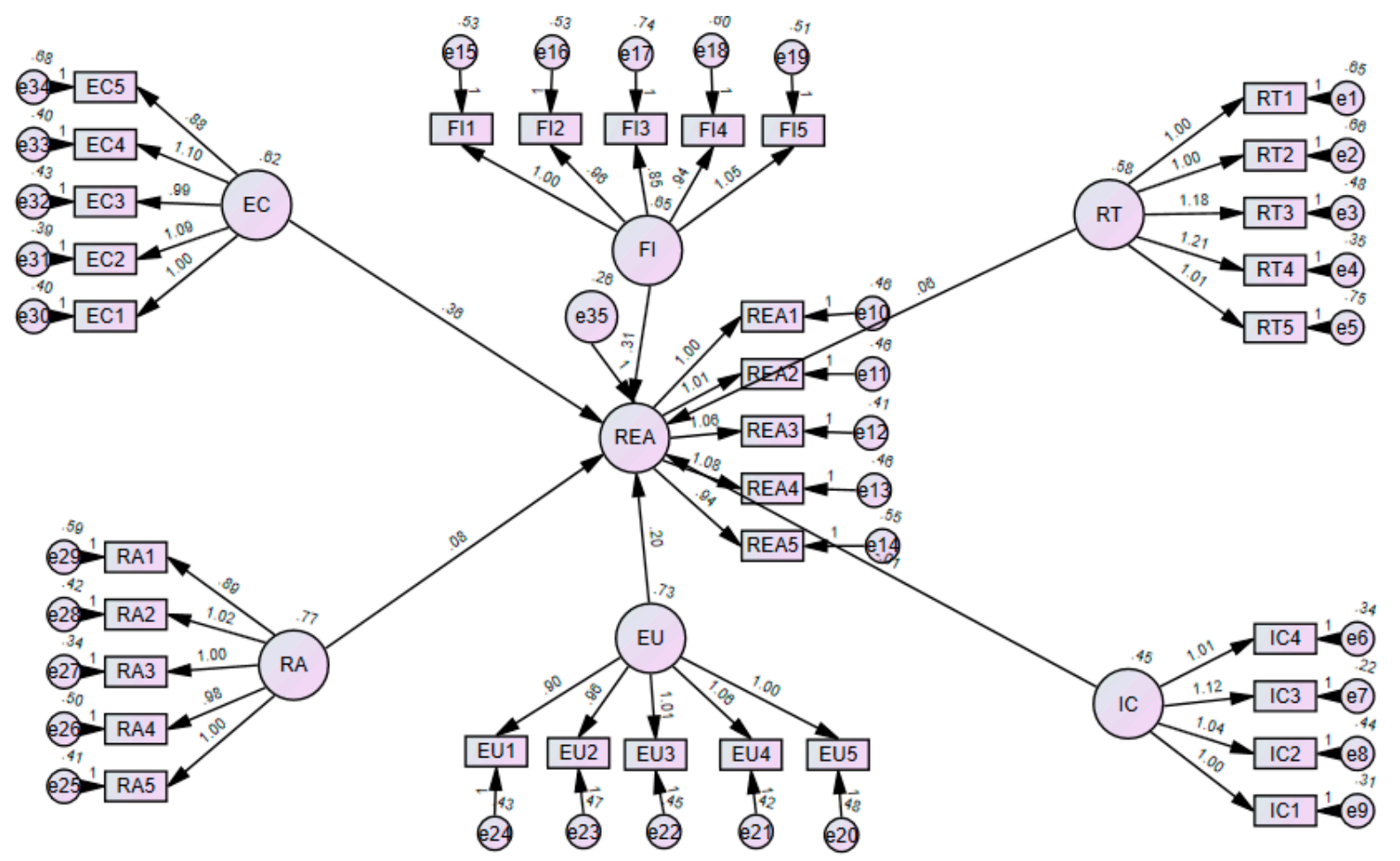

Figure 3. Evaluation of structural equation modeling results.

Though the model suitability metrics were tested in the CFA, it was also necessary to evaluate the suitability of the SEM model. The SEM indices indicated that CFA Indices $\mathrm{CMIN} / \mathrm{df}=1.889, \mathrm{RMSEA}=0.044, \mathrm{CFI}=0.954, \mathrm{TLI}=0.949, \mathrm{NFI}=0.908, \mathrm{IFI}=0.955$, which were all above recommended thresholds, according to [45-48]. This implied that the 
proposed model was fit to conduct the SEM analysis for evaluation of the study hypotheses. The results of the SEM hypotheses analysis are presented in the Table 5 below.

Table 5. Evaluation of study hypotheses.

\begin{tabular}{cccc}
\hline Hypothesis & Path Relationship & Estimate & Accept? \\
\hline H1 & IC $\rightarrow$ REA & -0.007 & No \\
H2 & EC $\rightarrow$ REA & $0.355^{* * *}$ & Yes \\
H3 & RT $\rightarrow$ REA & 0.065 & No \\
H4 & EU $\rightarrow$ REA & $0.203^{* * *}$ & Yes \\
H5 & FI $\rightarrow$ REA & $0.307^{* * *}$ & Yes \\
H6 & RA $\rightarrow$ REA & $0.082^{* * *}$ & Yes \\
\hline
\end{tabular}

Note: ${ }^{* * *}=p<0.01$. Source: research data.

The results revealed that among the six study hypotheses, four of them were accepted. The first accepted hypothesis was $\mathrm{H} 2$, represented by the path coefficient between environmental concerns (EC) and renewable energy adoption (REA) $(\beta=0.355, p<0.01)$. This indicated that environmental concern has a significant and positive effect on renewable energy adoption in Poland. The second was H4, represented by the path coefficient between ease of use (EU) and renewable energy adoption (REA) $(\beta=0.203, p<0.01)$, indicating that ease of use has a significant and positive effect on renewable energy adoption in Poland. The third was H5, represented by the path coefficient between financial incentives (FI) and renewable energy adoption (REA) $(\beta=0.307, p<0.01)$. This indicated that financial incentives have a significant and positive effect on renewable energy adoption in Poland. The last was H6, represented by the path between relative advantages (RA) and renewable energy adoption (REA) $(\beta=0.082, p<0.01)$. This implied that relative advantage has a significant and positive effect on renewable energy adoption in Poland. However, H1 and $\mathrm{H} 3$ were rejected, which implied that initial cost and risk and trust did not significantly influence renewable energy adoption in Poland.

This research found that environmental concern has a significant and positive effect on renewable energy adoption in Poland. This implied that aspects such as environmental conservation and prevention of pollution by energy sources would result in positive renewable energy technology adoption. According to the findings, a unit increase in environmental conservation aspects would result in 0.355 units in renewable energy adoption in Poland. Another vital finding of this research was that ease of use has a significant and positive effect on renewable energy adoption in Poland. These findings were supported by [54], who indicated that environmental motivations are slightly more important than economics and that perception of solar installers is also important to adopters.

Ease of use implied aspects such as how easy it is to understand, operate, and maintain the technology. The findings of this study were supported by [13], who indicated that perceived ease of use significantly influenced the intention to use solar energy technology. This finding is also important when considering future studies to ascertain internal factors that influence the adoption of renewable energy sources in Poland. Study [41] discussed the importance of factors such as perceived usefulness, perceived ease of use, and attitude; a future recommendation is a study that explores the influence of these internal variables in exploring the framework to ascertain if the findings will be consistent with the results in [37-41] on the significance of these variables towards measuring TAM postulates.

Additionally, financial incentives were found to have significant and positive effect on renewable energy adoption in Poland. The financial incentives included government and non-governmental organizations support, installation support, and discounts of on the initial cost. This study found that a unit increase in financial incentives resulted in 0.307 units increase in renewable energy technology adoption in Poland. These findings agreed with that of [14], who indicated that a well-established regulatory system to support consumers helps in efficient adoption of renewable energy technology.

The findings of the study also indicated that relative advantage aspects of renewable energy technology positively influenced renewable energy adoption in Poland. Specifically, 
one unit increase in relative advantage aspects led to 0.082 units increase in renewable energy adoption. These findings were supported by [28], whose studies found that relative advantage of a technology as compared to other technology is a major factor in its adoption.

\section{Conclusions, Implications, and Policy Recommendations}

Considering the increasing awareness of the environmental pollution and increasing demand for renewable energy, this study provides critical insights regarding the factors that should be considered as far as the adoption of renewable energy adoption is concerned in Poland. Some aspects are vital to consider in the effort to promote renewable energy technology in Poland. These aspects, as identified by this study, include environmental concern, ease of use of the technology, financial incentives, and the relative advantage of the renewable energy technology as compared to other sources of energy. As Poland undergoes the great regulatory revolution towards renewable energy technology such as wind and solar energy and works towards significantly reducing the use of non-renewable and polluting energy such as coal, the aspects considered in this study are vital to consider.

This study focused on evaluating consumers' adoption of renewable technology in Poland. The study was necessitated by how harnessing renewable energy continues to become important worldwide, replacing the non-renewable forms of energy such as oil, gas, and coal. The study, guided by the TAM model. used primary data collected from renewable energy household users in Poland. The study found out that there are four major factors influence the adoption of renewable energy technology in Poland. These include environmental concern, ease of use, financial incentives, and relative advantage [26,55,56].

Based on the findings of this research, several policy recommendations were made. First, the aspects of environmental concern should play a key role in pushing for adoption of renewable energy, as more people are aware and concerned about environmental impacts and its conservation. There is a dire need to minimize environmental pollution caused by non-renewable sources of energy. RE adoption is the major alternative. Creating awareness among the residents is of great importance and should be collaboratively undertaken by the government, non-governmental organizations, (as well as enterprises. The issues solved and benefits of RE should be explicitly disclosed to the public.

Second, government, non-governmental organizations, and concerned stakeholders should consider giving incentives towards renewable energy sources, as this has a significant influence on its adoption by households. This is necessitated by the fact that RE is capital intensive, and the upfront cost is quite high. Therefore, there is need for the government and other stakeholders to provide long-term and proper financing strategies for interested consumers. It is also important to consider reducing the interest rates associated with RE as a motivational mechanism.

Third, technology should be made available to households in an easy-to-use manner, as complexity may discourage its adoption [57,58]. Finally, relative advantage is a critical aspect in renewable energy technology, and awareness regarding the benefits and strengths of renewable energy should be prioritized by households.

The overall process of conducting the study is considered quite satisfactory from the researchers' perspective. However, two limitations are evident. First, this study was conducted in Poland, and specifically applies to the renewable energy situation in Polish households. Therefore, the application of the findings should be made with caution and recognition of the study environment. The second limitation is that the study applied the TAM model and used six variables. However, there are other models, such as unified theory of acceptance and use of technology (UTAUT), which would allow inclusion of several study variables. In addition, this study excluded internal variables such as perceived usefulness, subjective norm, and attitude. The second part of this study will address this shortcoming and provide a more holistic outlook towards the discourse on renewable energy adoption in Poland and guide the formulation of government policy towards renewable energy use in households in Poland. 
Author Contributions: All authors have contributed substantially to the entire work reported. Conceptualization, B.K.; methodology, B.K.; formal analysis, E.W. and M.U.; data curation, B.K. and M.U.; writing—original draft preparation, B.K., E.W. and B.P.; writing—review and editing, M.U. and M.K.-S.; project administration, E.W.; funding acquisition, M.K.-S. and B.P. All authors have read and agreed to the published version of the manuscript.

Funding: The project is funded under the program of the Minister of Science and Higher Education titled "Regional Initiative of Excellence" in 2019-2022, project number 018/RID/2018/19, the amount of funding PLN 10788 423,16.

Institutional Review Board Statement: Not applicable.

Informed Consent Statement: Informed consent was obtained from all subjects involved in the study.

Data Availability Statement: Not applicable.

Conflicts of Interest: The authors declare no conflict of interest.

\section{Appendix A}

Table A1. The scales adopted for the study.

Construct
Initial Cost
IC1: I find that initial cost of owning and installing renewable energy are expensive
IC2: I think that renewable energy should have cheaper price to encourage their purchase
IC3: I have sources of funds for the purchase of renewable energy
IC4: I find the purchase of renewable energy a good investment for future
IC5: I find that renewable energy is more expensive compared with conventional energy

Environmental Concern

EC1: I am anxious about pollution in the environment

EC2: Environmental pollution caused by energy is not good

EC3: I am anxious about environmental problems caused by energy sources

EC4: I am anxious about climate change and the associated hazardous effects

EC5: Utilization of renewable energy can improve the environment

Risk and Trust

RT1: I believe that renewable energy is a risk-free source of energy

RT2: I am aware of the risks associated with renewable energy

RT3: I don't think I am at risk when using renewable energy

RT4: I trust renewable energy because it can provide for my best interest in mind

RT5: I have more trust in renewable energy more than other energy sources

Ease of Use

EU1: It is easy to install renewable energy equipment

EU2: Learning to use renewable energy is easy for me

EU3: Manuals on renewable energy are easy to understand

EU4: Renewable energy installations are easy to operate

EU5: I can master using renewable energy equipment easily

Financial Incentives

FI1: Loans are available to require renewable energy

FI2: Grants are available to acquire renewable energy

FI3: Government subsidies renewable energy adoption

FI4: Feed-in-Tariff (Fit) is available for adopters of renewable energy

FI5: Tax relief is available to those who acquire renewable energy

RA1: Using renewable energy reduces fossil fuels usage

RA2: Using renewable energy decreases environmental pollution

RA3: Using renewable energy decreases carbon footprint

RA4: Using renewable energy the costs of energy supply

RA5: Energy generation from renewable energy is easier than from fossil fuels. 
Table A1. Cont.

\begin{tabular}{lc} 
Construct & Sources \\
\hline Renewable Energy Adoption & {$[18,20]$} \\
REA1: I have the intention to spend more on renewable energy technologies than other sources of energy & \\
REA2: I am planning to use renewable energy technologies & \\
REA3: I am encouraged to adopt renewable energy \\
REA4: I am willing to be renewable energy adoption ambassador \\
REA5: I strongly recommend others to adopt renewable energy technologies
\end{tabular}

\section{References}

1. Chel, A.; Kaushik, G. Renewable energy technologies for sustainable development of energy efficient building. Alex. Eng. J. 2018, 57, 655-669. [CrossRef]

2. Dato, P. Investment in Energy Efficiency, Adoption of Renewable Energy and Household Behavior: Evidence from OECD Countries. Energy J. 2018, 39. [CrossRef]

3. Sommerfeld, J.; Buys, L.; Vine, D. Residential consumers' experiences in the adoption and use of solar PV. Energy Policy 2017, 105, 10-16. [CrossRef]

4. Reyes-Mercado, P.R. Adoption of renewable energy technologies in mexico: The role of cognitive factors and innovation attributes. Int. J. Energy Sect. Manag. 2017, 11, 626-649. [CrossRef]

5. Oguntona, O.; Aigbavboa, C.; Monnanyana, T.; Thwala, W. Drivers of Renewable Energy Adoption in the Built Environment: A Case of South Africa. In IOP Conference Series: Materials Science and Engineering; IOP Publishing: Bristol, UK, 2021; Volume 1107, p. 012217. [CrossRef]

6. Sardianou, E.; Genoudi, P. Which factors affect the willingness of consumers to adopt renewable energies? Renew. Energy 2013, 57, 1-4. [CrossRef]

7. Makki, A.A.; Mosly, I. Factors Affecting Public Willingness to Adopt Renewable Energy Technologies: An Exploratory Analysis. Sustainability 2020, 12, 845. [CrossRef]

8. Pietrzak, M.; Igliński, B.; Kujawski, W.; Iwański, P. Energy Transition in Poland-Assessment of the Renewable Energy Sector. Energies 2021, 14, 2046. [CrossRef]

9. Li, J.; Omoju, O.E.; Zhang, J.; Ikhide, E.E.; Lu, G.; Lawal, A.I.; Ozue, V.A. does intellectual property rights protection constitute a barrier to renewable energy? An econometric analysis. Nat. Inst. Econ. Rev. 2020, 251, R37-R46. [CrossRef]

10. Gielen, D.S. Remap 2030 Renewable Energy Prospects for Poland; IRENA: Abu Dhabi, United Arab Emirates, 2015; Available online: www.irena.org/remap (accessed on 10 August 2021).

11. Xu, X.; Wei, Z.; Ji, Q.; Wang, C.; Gao, G. Global renewable energy development: Influencing factors, trend predictions and countermeasures. Resour. Policy 2019, 63. [CrossRef]

12. Board, C.E. Impact of Perceived Ease of Use, Awareness and Perceived Cost on Intention to Use Solar Energy Technology in Sri Lanka. J. Int. Bus. Manag. 2020, 3, 1-13.

13. Gboney, W. Policy and regulatory framework for renewable energy and energy efficiency development in Ghana. Clim. Policy 2009, 9, 508-516. [CrossRef]

14. Khalid, B.; Lis, M.; Chaiyasoonthorn, W.; Chaveesuk, S. Factors influencing behavioural intention to use MOOCs. Eng. Manag. Prod. Serv. 2021, 13, 83-95. [CrossRef]

15. Chaveesuk, S.; Khalid, B.; Chaiyasoonthorn, W. Emergence of New Business Environment with Big Data and Artificial Intelligence. In Proceedings of the 9th International Conference on Information, Prague, Czech Republic, 23-26 August 2019.

16. Abnett, A.B. Green Energy Investors Target Poland as It Weans Itself Off Coal. 2021. Available online: https://www.reuters. com/business/sustainable-business/green-energy-investors-target-poland-it-weans-itself-off-coal-2021-02-10/ (accessed on 10 August 2021).

17. Elmustapha, H.; Hoppe, T.; Bressers, H. Understanding Stakeholders' Views and the Influence of the Socio-Cultural Dimension on the Adoption of Solar Energy Technology in Lebanon. Sustainability 2018, 10, 364. [CrossRef]

18. Wall, W.P.; Khalid, B.; Urbański, M.; Kot, M. Factors Influencing Consumer's Adoption of Renewable Energy. Energies 2021, 14, 5420. [CrossRef]

19. Muangmee, C.; Dacko-Pikiewicz, Z.; Meekaewkunchorn, N.; Kassakorn, N.; Khalid, B. Green Entrepreneurial Orientation and Green Innovation in Small and Medium-Sized Enterprises (SMEs). Soc. Sci. 2021, 10, 136. [CrossRef]

20. Khalid, B.; Chaveesuk, S.; Chaiyasoonthorn, W. Moocs Adoption in Higher Education: A Management Perspective. Pol. J. Manag. Stud. 2021, 23, 239-256. [CrossRef]

21. Bulut, C.; Nazli, M.; Aydin, E.; Haque, A.U. The effect of environmental concern on conscious green consumption of postmillennials: The moderating role of greenwashing perceptions. Young Consum. 2021, 22, 306-319. [CrossRef]

22. Khalid, B.; Kot, M. The Impact of Accounting Information Systems on Performance Management in the Banking Sector. IBIMA Bus. Rev. 2021, 1-15. [CrossRef]

23. Wall, W.P. The Comparison of the Tqm Practices and Quality Performance between Manufacturing and Service Sectors. Pol. J. Manag. Stud. 2021, 23, 436-452. [CrossRef] 
24. Roozbeh, K. Renewable Energy Technology Acceptance in Peninsular Malaysia/Roozbeh Kardooni. Ph.D. Thesis, University of Malaysia, Kuala Lumpur, Malaysia, 2016.

25. Yang, L.; Danwana, S.B.; Yassaanah, I.F.-L. An Empirical Study of Renewable Energy Technology Acceptance in Ghana Using an Extended Technology Acceptance Model. Sustainability 2021, 13, 10791. [CrossRef]

26. Sabishchenko, O.; Rębilas, R.; Sczygiol, N.; Urbański, M. Ukraine Energy Sector Management Using Hybrid Renewable Energy Systems. Energies 2020, 13, 1776. [CrossRef]

27. Meekaewkunchorn, N.; SzczepańskaWoszczyna, K.; Muangmee, C.; Kassakorn, N.; Khalid, B. Entrepreneurial orientation and SME performance: The mediating role of learning orientation. Econ. Sociol. 2021, 14, 294-312. [CrossRef]

28. Claudy, M.C.; Peterson, M.; O’Driscoll, A. I like it, but I won't buy it": Exploring the attitude-behaviour gap for renewable energy adoption. In Proceedings of the 37th Macromarketing Conference, Berlin, Germany, 13-16 June 2012; Volume 324.

29. Ahmad, A.; Rashid, M.; Omar, N.A.; Alam, S.S. Perceptions on Renewable Energy Use in Malaysia: Mediating Role of Attitude. J. Pengur. 2014, 41, 123-131. [CrossRef]

30. Kiprop, E.; Matsui, K.; Maundu, N. The Role of Household Consumers in Adopting Renewable Energy Technologies in Kenya. Environments 2019, 6, 95. [CrossRef]

31. Yang, S.; Park, S. The effects of renewable energy financial incentive policy and democratic governance on renewable energy aid effectiveness. Energy Policy 2020, 145, 111682. [CrossRef]

32. Fowler, L.; Breen, J. Political Influences and Financial Incentives for Renewable Energy. Electr. J. 2014, 27, 74-84. [CrossRef]

33. Muangmee, C.; Kot, S.; Meekaewkunchorn, N.; Kassakorn, N.; Khalid, B. Factors Determining the Behavioral Intention of Using Food Delivery Apps during COVID-19 Pandemics. J. Theor. Appl. Electron. Commer. Res. 2021, 16, 1297-1310. [CrossRef]

34. Idzikowski, A.; Cierlicki, T. Economy and energy analysis in the operation of renewable energy installations-A case study. Prod. Eng. Arch. 2021, 27, 90-99. [CrossRef]

35. Muhammad, S.A.; Fida, H.C.; Abdul, F.S.; Shah, F. Social influence, voluntariness, experience and the internet acceptance: An extension of technology acceptance model within a south-asian country context. J. Enterp. Inf. Manag. 2011, 24, 30-52.

36. Chaveesuk, S.; Khalid, B.; Chaiyasoonthorn, W. Digital payment system innovations: A marketing perspective on intention and actual use in the retail sector. Innov. Mark. 2021, 17, 109-123. [CrossRef]

37. Androniceanu, A.M.; Georgescu, I.; Dobrin, C.; Dragulanescu, I.V. Multifactorial components analysis of the renewable energy sector in the OECD countries and managerial implications. Pol. J. Manag. Stud. 2020, 22, 36-49. [CrossRef]

38. Chaiyasoonthorn, W.; Khalid, B.; Chaveesuk, S. Success of Smart Cities Development with Community's Acceptance of New Technologies. In Proceedings of the 9th International Conference on Information Communication and Management, Prague, Czech Republic, 23-26 August 2019.

39. Chaveesuk, S.; Chaiyasoonthorn, W.; Khalid, B. Understanding the Model of User Adoption and Acceptance of Technology by Thai Farmers. In Proceedings of the 2020 2nd International Conference on Management Science and Industrial Engineering, Osaka, Japan, 7-9 April 2020.

40. Alhassan, A.; Li, L.; Reddy, K.; Duppati, G. Consumer acceptance and continuance of mobile money: Secondary data insights from africa using the technology acceptance model. Australas. J. Inf. Syst. 2020, 24. [CrossRef]

41. Davis, F.D.; Bagozzi, R.P.; Warshaw, P.R. User acceptance of computer technology: A comparison of two theoretical models. Manag. Sci. 1989, 35, 982-1003. [CrossRef]

42. Wang, Y.; Meister, D.; Wang, Y. Relative Advantage and Perceived Usefulness: The Adoption of Competing ICTs. DIGIT 2008 Proceedings 6. Available online: http:/ /aisel.aisnet.org/digit2008/6 (accessed on 30 September 2021).

43. Karahanna, E.; Agarwal, R.; Angst, C.M. Reconceptualizing Compatibility Beliefs in Technology Acceptance Research. MIS Q. 2006, 30, 781-804. [CrossRef]

44. Chaveesuk, S.; Khalid, B.; Chaiyasoonthorn, W. Understanding Stakeholders Needs for Using Blockchain Based Smart Contracts in Construction Industry of Thailand: Extended TAM Framework. In Proceedings of the 13th International Conference on Human System Interaction (HSI), Tokyo, Japan, 6-8 June 2020. [CrossRef]

45. Schrier, T.; Erdem, M.; Brewer, P. Merging task-technology fit and technology acceptance models to assess guest empowerment technology usage in hotels. J. Hosp. Tour. Technol. 2010, 1, 201-217. [CrossRef]

46. Ahn, M.; Kang, J.; Hustvedt, G. A model of sustainable household technology acceptance. Int. J. Consum. Stud. 2015, 40, 83-91. [CrossRef]

47. Schumacker, R.E.; Lomax, R.G. A Beginner's Guide to Structural Equation Modeling, 3rd ed.; Routledge: New York, NY, USA, 2010.

48. $\mathrm{Hu}, \mathrm{L}$; Bentler, P.M. Cutoff criteria for fit indexes in covariance structure analysis: Conventional criteria versus new alternatives. Struct. Equ. Model. Multidiscip. J. 1999, 6, 1-55. [CrossRef]

49. Kline, R.B. Principles and Practice of Structural Equation Modeling, 2nd ed.; Guilford Press: New York, NY, USA, 2005.

50. Thompson, B. Exploratory and Confirmatory Factor Analysis: Understanding Concepts and Applications; American Psychological Association: Washington, DC, USA, 2004.

51. Fornell, C.; Larcker, D.F. Evaluating structural equation models with unobservable variables and measurement error. J. Mark. Res. 1981, 18, 39-50. [CrossRef]

52. Segars, A. Assessing the unidimensionality of measurement: A paradigm and illustration within the context of information systems research. Omega 1997, 25, 107-121. [CrossRef] 
53. Schelly, C.; Letzelter, J.C. Examining the Key Drivers of Residential Solar Adoption in Upstate New York. Sustainability 2020, 12, 2552. [CrossRef]

54. Khalid, B.; Naumova, E. Digital transformation SCM in view of Covid-19 from Thailand SMEs perspective. In Global Challenges of Digital Transformation of Markets; Nova Science Publishers, Inc.: New York, NY, USA, 2021; pp. 49-66.

55. Smirnova, E.; Szczepańska-Woszczyna, K.; Yessetova, S.; Samusenkov, V.; Rogulin, R. Supplying energy to vulnerable segments of the population: Macro-financial risks and public welfare. Energies 2021, 14, 1834. [CrossRef]

56. Hussain, H.I.; Haseeb, M.; Kamarudin, F.; Dacko-Pikiewicz, Z.; Szczepańska-Woszczyna, K. The role of globalization, economic growth and natural resources on the ecological footprint in Thailand: Evidence from nonlinear causal estimations. Processes 2021, 9, 1103. [CrossRef]

57. Ulkhaq, M.M.; Widodo, A.K.; Yulianto, M.F.A.; Widhiyaningrum, M.A.; Akshinta, P.Y. A logistic regression approach to model the willingness of consumers to adopt renewable energy sources. In IOP Conference Series: Earth and Environmental Science; IOP Publishing: Bristol, UK, 2018; Volume 127. [CrossRef]

58. Young, J.D.; Anderson, N.M.; Naughton, H.T. Influence of policy, air quality, and local attitudes toward renewable energy on the adoption of woody biomass heating systems. Energies 2018, 11, 2873. [CrossRef] 